\title{
Animal And Human Derived Products (A/HdPs) In Otolaryngology, Counselling And Consent
}

\section{Mr Hassan Mohammed FRCS (ORL-HNS), Miss Kate Blackmore FRCS (ORL-HNS), James}

Cook University Hospital NHS Foundation Trust

\section{Background:}

Informed consent is an essential aspect in medical and surgical practice. Current guidelines from the UK General Medical Council and the Royal College of Surgeons of England do not give advice with regards to consent of use of grafts or animal products in surgery.

This study aimed to explore ENT surgeons' attitude and approach towards commonly used animal and human derived materials in their own practice.

\section{Material and Methods:}

An online hosted survey was designed to cover different aspects related to use of $\mathrm{A} / \mathrm{H}-\mathrm{dPs}$ in ENT surgery. ENT UK helped in distributing the survey via its members' mailing list.

\section{Results:}

A link to the survey was sent via ENT UK mailing list to 739 consultants. 178 of those who the email was sent to clicked on the link that directed them to the survey website and 100 consultants completed the survey. Around $90 \%$ of respondents don't discuss with their patients the need to use $\mathrm{A} / \mathrm{H}-\mathrm{dPs}$ in the consent process. Responses to other questions are presented in the tables below.

\section{Discussion:}

Even though there is significant exposure to $\mathrm{A} / \mathrm{H}-\mathrm{dPs}$ in ENT specialty, these products are not commonly discussed with surgical candidates. When discussed, documented religion was the main factor for that.

Even in groups with strong representation such as Jehovah Witnesses, only blood products are discussed. Even though there are other $\mathrm{A} / \mathrm{H}-\mathrm{dPs}$ that a Jehovah Witness might decline to use if discussed with him/her.

There is need to interventions in order to increase awareness among ENT surgeons of the significance of $\mathrm{A} / \mathrm{H}-\mathrm{dPs}$ to certain groups of patients.

Subspecialty, exposure to A/H-dPs and experience in using A/HdPs of ENT consultants who responded to the survey

\begin{tabular}{|l|l|l|l|l|}
\hline Question & & & & \\
\hline $\begin{array}{l}\text { Consultants } \\
\text { subspecialty }\end{array}$ & Otology & Head and neck & Rhinology & Paediatrics \\
\cline { 2 - 5 } & 28 & 16 & 10 & 5 \\
\hline \multirow{2}{*}{ Exposure to A/HdPs } & No exposure & Less than once/month & $1-4$ times/month & $\begin{array}{l}\text { More than 4 times/ } \\
\text { month }\end{array}$ \\
\cline { 2 - 5 } & 11 & 50 & 21 & 18 \\
\hline \multirow{2}{*}{$\begin{array}{l}\text { Experience in using A/ } \\
\text { HdPs }\end{array}$} & Less than one year & $1-5$ years & $5-10$ years & More than 10 years \\
\cline { 2 - 5 } & 4 & 11 & 14 & 60 \\
\hline
\end{tabular}

Effects of patients'/surgeons' characteristics of ethnicity, culture, diet and religion on utilization/discussion of A/HdPs

\begin{tabular}{|c|c|c|c|c|}
\hline Question & & & & \\
\hline \multirow{2}{*}{$\begin{array}{l}\text { Guidance by patient } \\
\text { characteristics } \\
\text { (including appearance) }\end{array}$} & No to all & Documented religion & & \\
\hline & 56 & 15 & & \\
\hline \multirow{2}{*}{$\begin{array}{l}\text { Change surgical plan } \\
\text { based on patient } \\
\text { characteristics }\end{array}$} & Yes & No & & \\
\hline & 81 & 19 & & \\
\hline \multirow{2}{*}{$\begin{array}{l}\text { Guidance by surgeon } \\
\text { characteristic }\end{array}$} & No to all & Yes to all & religion & Religion and culture \\
\hline & 88 & 8 & 3 & 1 \\
\hline
\end{tabular}

\section{Conclusion:}

This study highlights the issues of awareness, counseling and consent of the use of A/H-dPs in ENT surgery. It showed that a significant percentage of ENT surgeons are not aware of the origin of some of the commonly used A/H-dPs in ENT and that there is tendency to avoid discussing the need for such products with patients. More awareness is necessary both in term of ingredients of $\mathrm{A} /$ $\mathrm{H}-\mathrm{dPs}$ and in term of need to discuss such ingredients with patients as part of obtaining consent. 